\title{
Institutional Care and Response to Victims of Child Sexual Abuse in India: The Role of Non-governmental Organizations \& Public Hospitals
}

\author{
Aditi Das \\ School of Social Welfare, Mack Center for Nonprofit and Public Sector Management in the Human Services, \\ The University of California, Berkeley, United States
}

\begin{abstract}
Child Sexual Abuse (CSA) is a violation perpetuated in secrecy and shrouded in silence. In India, a 2007 report revealed that over half the children reported having faced sexual abuse, the abusers were known to the child and the cases were mostly unreported. This prevalence is accentuated by patriarchal norms that persist in India wherein upholding familial honour trumps providing support to a CSA victim. For those who seek support, institutional care namely non-governmental organizations (NGOs) and public hospitals often become the first point of contact for most victims and their families. Therefore the qualitative study located in Mumbai, India was motivated from the perspective of understanding the role of institutional support with regards to prevention and intervention in CSA. Findings highlight that most NGOs adopt a holistic strategic plan while dealing with CSA cases in terms of case-management and prevention efforts, whereas public hospitals mostly focus on the medico-legal elements of the case for evidentiary purposes. Early and timely intervention is critical for arresting future CSA symptoms from arising. Study findings have implications for more strategic reform and collaborative engagement across various institutions of care and support for CSA whilst breaking the silence on CSA in India.
\end{abstract}

Keywords Child Sexual Abuse, Institutional Care, India, Public Hospitals, Case Management, Non-governmental Organizations

\section{Introduction}

The Anchorage shelter case was a landmark judgement that was passed by the Supreme Court of India in 2011 that lead to the conviction of two British paedophiles for sexually abusing children under their care. This historic judgement marked the closure of a ten-year period of struggle of a child rights (NGO) ${ }^{1}$ and advocates delivering justice to the children of Anchorage ${ }^{2}$. Nearly nineteen percent of the world's children live in India, which constitutes 42 percent of India's total population and around 50 percent of these children are in need of care and protection (UNICEF, 2012). Being a signatory to the United Nations Convention on the Rights of the Child, India promised to protect its children from all forms of sexual exploitation and sexual abuse. Article 34 (a) enjoins state machinery to prevent the inducement or coercion of a child to engage in any unlawful sexual activity. Yet despite the success of the Anchorage case intervention, which contributed to an enhanced understanding of CSA, India has a dubious distinction of being one of the countries with the largest numbers of sexually abused children in the world (Kumar et al, 2012).

World Health Organization (2006) defines CSA as the "involvement of a child in sexual activity that he or she does not fully comprehend, is unable to give informed consent to, or for which the child is not developmentally prepared and cannot give consent, or that violate the laws or social taboos of society. CSA is evidenced by this activity between a child and an adult or another child who by age or development is in a relationship of responsibility, trust or power, the activity being intended to gratify or satisfy the needs of the other person.” The Juvenile Justice Care and Protection Act, 2000 amended in 2006 and 2015 deals with children in need of care and protection and was specifically drafted to implement India's obligations under the United Nations Convention on the Rights of the Child and other international instruments. The Act defines a child as "a person, who has

1 A non-governmental organization (NGO) is any non-profit, voluntary citizens' group, which is organized on a local, national or international level that operates independently from the Government.

2 Retrieved from http://www.childlineindia.org.in/anchorage-case-histor y-updated.htm

ISSN: 2332-6840 (Online) 2332-6832 (Print) Copyright (C) 2017 by authors, all rights reserved. Authors agree that this article remains permanently open access under the terms of the Creative Commons Attribution License 4.0 International License 
not completed eighteenth year of age”. The Act mandates the Child Welfare Committee to take action for rehabilitating sexually abused children who are reported as children in need of care and protection by a Special Juvenile Police Unit or local police, as the case may be, under the Protection of Children from Sexual Offences Act, 2012. As per the Juvenile Justice Act registered NGOs can conduct a social investigation on behalf of the victim of CSA and can provide them shelter and support (Juvenile Justice Act, 2015).

"India shamed by silence on child sexual abuse within the family" (Virmani, April 2017), “The deafening silence of child abuse” (Hiranandani, August 2017), "What will it take to end child sexual abuse in India?” (Jha, September 2017). These are examples of some recent newspaper headlines from popular Indian media outlets. The articles largely emphasize the magnitude and pervasiveness of the problem of CSA in India exacerbated by a common saying in Indian households, Ki log Kya Kahenge? (Translated to what will people say?). Although identity in India is evolving and multi-faceted (Saraswathi, 2013), India has traditionally been an interdependent society based on collectivist values, close family relationships, and highly prescribed roles determined by gender, caste and position in the family (Verma \& Saraswathi, 2002). Given that Indian identity evolve around 'us' and 'ours' rather than ' me' or 'mine' (Roland, 1998), CSA cases are often veiled in secrecy because upholding familial honour and pride is considered more salient than catering to the needs of CSA victims. Generations of Indian children have watched their parents remain silent on sexual issues, sweeping anything uncomfortable under the rug and looking away. This is further complicated by a tradition that demands that every child must respect and obey all elders, and so children obey and remain silent, no matter what their elders do (Hiranandani, August, 2017).

Studies have consistently demonstrated that sexual abuse and physical problems that persist into adulthood include problems like anxiety, depression, post- traumatic stress disorder, self-destructive behavior, dissociation, substance abuse, sexual maladjustment, and a tendency towards re-victimization in subsequent relationships (Bhullar, 2014). Hence it is very important that service provision in CSA ought to be provided in a timely fashion in order to prevent symptoms from manifesting at a later juncture. Thus the roles of formal institutional care settings, such as NGOs and public hospitals are significant since they are often the first point of contact for health seeking behavior amongst CSA victims and their guardians. Within the Indian context, there are very few studies that have examined the role played by formal institutional care settings as they strive to intervene and prevent cases of CSA. NGOs were originally established to fulfill gaps in governmental provision in human service delivery. Thus the study sought to examine the independent roles played by NGOs vis a vis governmental organizations like public hospitals and assess similarities and differences in CSA service delivery.

\section{Review of Related Literature}

This section is subdivided into two major sections. Firstly, assess the magnitude and reportage of CSA in India across caste, class, gender, educational and cultural backgrounds. The second component provides a global overview of the research on formal institutional care for victims of CSA.

\section{Prevalence and Reportage of CSA in India}

Given that sex and sexuality are taboo topics in India, discussions surrounding them are unusually hushed, secretive, and uninformed. Investigating abuse in such a context becomes difficult despite the understanding among practitioners that CSA is widespread. There are primarily two means by which CSA is known, one is through discovery wherein an adult outside the abusive relationship finds out about the abuse, and secondly is disclosure wherein the child speaks about their victimization. A wide range of individual and social factors determines the detection of CSA. Primarily, the secrecy and denial, which shroud the issue of CSA, make both disclosure and discovery rare. Studies on CSA tend to be retrospective, conducted with either adult survivor of CSA or with a variety of stakeholders (Prabhu, 2008).

It is only in the last decade or so that the Indian state has acknowledged that CSA is an issue, which requires government intervention. In 2007, a landmark survey revealed rampant physical and sexual abuse across 13 states. 12,447 children were interviewed; 53\% had suffered some kind of sexual violence and around one in five said they had suffered serious sexual assault. The most worrying statistic was that $70 \%$ of children had not disclosed the abuse to anyone, confused about what to say, afraid of their abuser, or afraid that they would not be supported but blamed (Kacker et al., 2007; Jha, September 2017). Smaller surveys conducted by NGOs also paint a disturbing picture about how widespread the issue of CSA is in India. One of the earliest studies conducted by a Bangalore-based NGO Samvada studied 348 girls aged between 15 and 21 across multiple schools and colleges in Karnataka, found that $47 \%$ of the girls had been sexually molested, and some had sexual abuse experiences as early as age 10 (Arpan, 2014). RAHI, another Delhi based NGO conducted a multi-state study on understanding women's experiences of incest and CSA, found that $76 \%$ of women belonging to the middle and upper socio-economic classes had been sexually abused as children, and $71 \%$ of the time their abuser was someone they trusted, like a close relative (RAHI, 1998). A study in 2006 by an NGO Tulir - Centre for Prevention and Healing of Child Sexual Abuse conducted on school going children across different socio-economic backgrounds, revealed at least 
48 percent of the boys and 39 percent of the girls interviewed said they had faced sexual abuse of one form or another (Save the Children \& Tulir, 2006).

Child welfare institutions meant for the care and protection of vulnerable children in India have also reported cases of sexual abuse. A national newspaper reported sexual abuse cases in eight different residential facilities in different parts of India. The vast majority of victims (72 percent) said that they did not report the matter to anyone and only 3 percent of them informed the police (Arpan, 2014). As research has shown, it is not just within institutions that Indian children suffer from sexual abuse but trusted adults within the confines of their home, school and neighborhoods are sexually abusing children. Carson et al.'s (2013) survey of the current state of knowledge on CSA concluded that around $50 \%$ cases occurred in institutional settings and $18-20 \%$ of cases occurred within households. The study states that factors that enhance the likelihood of CSA include poverty, overcrowding, extended family living arrangements, and living on the streets.

Reportage of cases is very poor and in many cases there is a lack of knowledge and awareness amongst most people in the country about CSA. Fear of social stigma, lack of faith in governmental institutions and deep-rooted cultural norms discourage the open conversation on sex, making it harder for a child to complain to a person in a position of authority and responsibility (Human Rights Watch, 2013; Choudhury, 2006). Other reasons for under-reporting include the fear that children and their relatives will not be treated sympathetically; coercive tactics used by police officers, degrading and painful medical examinations, intimidation by perpetrators to drop charges and prolonged court cases that can lead to re-victimization. Additionally, most children who do decide to complain or otherwise display signs of their abuse do not receive the support they need (Human Rights Report, 2013). Differences exist across regions and there is a variation of rates of CSA in urban compared to rural areas, and often more girls are vulnerable to sexual abuse than boys. Alaggia \& Kirshenbaum's (2005) study sought to examine the family dynamics that contribute or hinder the child's ability to disclose sexual abuse. Findings highlight gendered and cultural values with respect to child rearing practices and obedience to authority; attitudes that discourage discussion of 'private familial matters', act as deterrents to disclose victimization. Panchal and Sheikh (1997), in their documentation of police cases of sexually abused girls revealed that CSA cuts across all categories of class, caste, religion, educational background, and age of both victims and offenders.

Sexually abused children are severely let down by systemic failures of the criminal justice system to redress their grievances exacerbated by social ostracism associated with such abuse (Human Rights Watch, 2013).
Only 3 \% of CSA offences uncovered by Kacker et al.'s (2007) study was reported to the police. It is unsurprising that CSA is severely underreported given the shame and socio-cultural stigma, especially if the abuse has taken place within the family. This phenomenon is not unique to India but common to collectivist cultures, where an individual's experience is ignored so as to protect the family from shame associated with CSA (Back et al. 2003; Stoltenberg et al. 2011). Yet, almost nothing has been done by the Indian government to encourage the reporting of cases, to shift the mindset that allows perpetrators to act with impunity and, most crucially, to challenge the space that is the predominant site for such abuse, the family (Virmani, April 2017).

\section{Institutional Support and Service Provision for CSA}

A majority of studies globally have been carried out to map the availability and provision of formal services for children who have been sexually abused. Research by Baginsky (2001) on support services for 12 to 16 year olds who had been sexually abused found 'patchy' provision in the UK, with particular service gaps for children from ethnic minority groups, children with disabilities and young people who displayed sexually harmful behavior. A more comprehensive study conducted across England, Wales, Northern Ireland and Scotland revealed a significant gap in the availability, accessibility and provision of therapeutic services for children who have experienced sexual abuse (Allnock et. al, 2012).

Czincz \& Romano, (2013) studied the utility of trauma-focused cognitive behavioral therapy, an evidence-based intervention for children who have experienced CSA within community based treatment practices. Results from the study highlighted the pressing need for knowledge translation of evidence-based practices and its adoption in community settings and a service approach that is more focused on accountability and cohesion between the realms of research and practice. Another study looked at program outcomes and predictors of disclosure amongst young children during a sexual abuse forensic evaluation, especially as assessment of the veracity of allegations impeded by developmental limitations, trauma reactions, unsupportive caregiver responsiveness, or fear of the perceived repercussions of telling (Azzopardi, Madigan \& Kirkland-Burke, 2014). A qualitative study on gaining adolescent perspectives on social support received in the aftermath of sexual abuse revealed that sexually-victimized children and adolescents require a network of socially-supportive people since victims often perceive received support as insufficient for coping with the abuse (Schonbucher et.al, 2014) The importance of professional psychological support was also confirmed in the studies of Morrison and Clavenna-Valleroy (1998) and Crisma et al. (2004).

Within India, there are very few studies that have 
focused on understanding the kinds of institutional support and provisions provided in the field of CSA. For instance, Jaswal (2005) researched the profile and patterns of cases of CSA being reported at public health facilities such as urban health centers, maternity hospitals, dispensaries and municipal hospitals. Both male and female children reported their first sexual encounter at about the same age, indicating that children of both sexes are equally vulnerable to abuse in the absence of protection by parents, guardians or organizations. In addition, the findings indicate that children who are isolated from others, especially children living on the streets without adult care are more susceptible to CSA. The attitude of the health providers added to the discomfort and feelings of shame and guilt felt by the victims and their families. Prabhu's (2008) study on a national NGO's CSA intervention helped identify and highlight the needs and gaps in interventions faced by the NGO as well as other allied systems like the police, health facilities, amongst others whilst handling cases of CSA. The study revealed that intervention in CSA requires sensitivity and expertise on the issue necessitating an urgent need for training and capacity building. A study by Bhaskaran \& Seshadri (2016) recognizes and documents common clinical challenges that emerge during their work with sexually abused children, and provide suggestions to render assistance and services in an effective manner. For instance, instead of asking CSA survivors directly about their distressing history of abuse, ask children for details about their early childhood, schooling, family environment, adolescence, relationships and sexuality.

In May 2012, India took a major step by passing the Protection of Children from Sexual Offences Act. Under the law, all forms of CSA are now specific criminal offenses for the first time ever in India. The Act criminalizes sexual assault, sexual harassment, and pornography involving a child (less than 18 years of age) and mandates the setting up of Special Courts to expedite the trials of these offenses (Belur \& Singh, 2015). However a gap still exists between law and the rightful implementation of the Protection of Children from Sexual Offences Act. According to a recent newspaper article, even though the child welfare machinery is becoming more aware of the Protection of Children from Sexual Offences Act, spaces like police stations and special courts have not been transformed into child-friendly settings (Jha, September 2017). The rightful implementation of the Act involves various criminal justice, state and third sector agencies thereby necessitating sound collaboration of efforts and resources (Belur \& Singh, 2015). Resource scarcity and a lack of appropriate training can unduly affect how investigations, prosecution and medical examinations are conducted in cases of CSA. Though the Act envisages a comprehensive multi-sectorial approach, the way the Act gets implemented on the ground needs further fine-tuning and a thorough evaluation.
Since studies in the Indian context have primarily focused on highlighting the gravity of the problem of CSA in India, the current study is looking to fill a gap in the literature by seeking to understand variation in the kinds of formal institutional support and service provision provided to victims of CSA, and efforts made to prevent sexual abuse from occurring in the first place. Therefore the research questions posed in the study are as follows:

- What is the process of help-seeking behaviour by victims of CSA and how does this vary by institutional context?

- What are the kinds of institutional support and interventions provided with respect to CSA and how does this vary by institutional context?

\section{Materials and Methods}

Given the process oriented nature of the research questions posed in the study, the researcher felt that a more thorough, qualitative examination of institutional care and support provided to victims of CSA and efforts made to prevent CSA was warranted. Marshall and Rossman (1989) suggest that this entails immersion in the everyday life of the setting chosen for the study, which in this particular study involves the NGO and the public hospital setting. The researcher enters the informant's world, that is, the program manager of the NGO and the doctor of the hospital and through on going interactions, seeks the informants' perspectives and meanings, that is, their understanding and interpretation of service provision for CSA.

\section{Sampling and Data Collection Process}

Children and young people who experience sexual abuse may need access to a range of services or sources of support. There are everyday "universal" services for children and young people, such as schools, as well as the more specialist services provided to protect children and respond to needs. This research, however, focuses on the availability of "responsive" services that exist in the statutory, voluntary and private sectors to help children and young people affected by sexual abuse to cope with and overcome the problems arising from it.

A broad mapping of various NGOs located in the city of Mumbai ${ }^{3}$ working in the field of child rights and child and youth development practice, as well as public and private hospitals whose area of work included CSA was conducted. Subsequently, the researcher using the purposive sampling technique contacted various NGO managers as well as medical superintendents at the

3 Mumbai was chosen as the field site partly due to convenience given the researcher was interning at a local NGO engaged in CSA awareness building efforts but largely due the fact that Mumbai is a thriving urban metropolis with a vast network of NGOs and public hospitals working in the field of CSA. 
hospitals, and the final sample comprised of nine NGOs and three major public hospitals. In both sets of organizations, the researcher was focusing on getting maximum variation in terms of the spectrum of services provided in the field of CSA, such as prevention through CSA awareness generation, direct intervention work in the form of case handling as well as medico-legal intervention (See Table 3.1.1 for details).

In India, there is no official institutional review board, yet the researcher applied all the required ethical considerations. Requisite permissions and authorization letters were sought from the authorities with regards to conducting face-to-face in-depth semi- structured interviews with NGO managers and medical superintendents respectively. The NGOs were a lot more cooperative compared to hospital settings with regards to being willing to become research participants. Public hospitals, on the other were more suspicious about how the data collected was going to be handled, given that as a public institution they are under a lot more public scrutiny than NGOs.

The data collection took place over a period of 3 months from January to March 2009. Informed verbal consent was sought from each of the participants before interview conduction. The semi-structured interviews were conducted in the offices of chosen NGOs, and offices of the medical superintendents at their respective hospitals. The interviews were conducted in English and the researcher took extensive notes during the interviews. There was no audio recording of the interviews. The interviews focused on understanding the specific strategies the respective institutions played vis a vis their CSA service provision, and details about specific CSA cases were also sought. The names of organizations and hospitals have not been used but emphasis has been laid on their area of specialization as stated in Table 3.1.1.
Content analysis was used to analyze the interview transcripts. It makes replicable and valid inferences from participant communication in specific contexts (Berelson, 1971; Krippendorff, 2012). Content analysis is most appropriate for researchers wishing to study subjects without affecting their communication or behavior, which could ultimately reduce the validity of the data (Babbie, 2010), which in this case involved face to face interviews with the staff at the NGOs and hospitals using a semi-structured interview guide. The core components of content analysis were used to ensure reliable and valid analysis wherein the codes were created based on meaning units. According to Graneheim and Lundman (2004), meaning units are words, sentences, or paragraphs containing aspects related to one another through their content and context. In the present study, meaning units lead to the creation of codes based on the sequence of themes of the interview questions. The final thematic code categories that emerged included the following- 1) Why CSA? 2) Help seeking behavior and CSA Case Description, 3) CSA Intervention \& Prevention, and 4) Gaps \& felt needs.

\section{Study Limitations}

The final sample chosen was based on the participant's willingness to being interviewed; therefore the data may be prone to selection bias. The participants were also made to jog their memories on recalling specific information on CSA cases, which may have led to some data distortion. Even though this study emphasized the Protection of Children from Sexual Offences Act of 2012, the data that was collected for this study took place in 2009 and hence the effects of the Act would not have played into the data. The data was collected from only Mumbai thus it is harder to make generalizations to other contexts.

\section{Data Analysis}

Table 3.1.1. Description of institutional area of specialization and specific services for CSA prevention and intervention

\begin{tabular}{|c|c|}
\hline \multicolumn{2}{|c|}{ Non-governmental Organizations } \\
\hline Area of specialization & Provision of services in the field of CSA \\
\hline Vulnerable children & Awareness building \\
\hline Street children & Direct case intervention \\
\hline Runaway youth & Direct case intervention, research informed practice \& awareness building \\
\hline Street children & Direct case intervention, research informed practice \& awareness building \\
\hline Child rights and protection from child labour & Direct case intervention, research informed practice \& awareness building \\
\hline Helpline for children in need of care and protection & Direct case intervention \& awareness building \\
\hline CSA & Direct case intervention \& awareness building \\
\hline Children of Female Commercial Sex Workers & Integrated Multidisciplinary approach \\
\hline Multi-Disciplinary Child Protection Center & Medico-legal and psycho-social direct case intervention \\
\hline Maternity Hospital & Medico-legal direct case intervention \\
\hline Police Hospital &
\end{tabular}




\section{Results}

In order to capture the variation in CSA service provision this section will provide a comparative analysis of how NGOs and public hospitals seek to assist CSA victims and raise awareness on CSA. The data will be represented thematically based on the themes identified in the methods section.

\section{Why CSA?}

A majority of the NGOs sampled in this study specialize in the area of children in need of care and protection such as street children, children of female commercial sex workers, and run-away children. It was observed that owing to the vulnerability of such children living on the streets or residing in shelter homes made them more susceptible to becoming victims of CSA. Hence several NGOs who engage in direct practice work with children felt the pressing need to integrate CSA as a part of their organizational mission. For instance an agency's program manager, whose area of operation is to rescue child victims from trafficking and commercial sexual exploitation stated,

CSA was incorporated into our work right from the start due to the vulnerability of the population we are dealing with. The community where children live is unsafe as they are constantly exposed to sex since their mothers are commercial sex workers. Men who frequent their mothers have been drunk and have taken advantage of such children.

The above quotation throws light on the precarious, unsafe environments that children grown up in, thereby making them easy targets of sexual violence Another agency that largely focuses on rescuing minors from child labour and exploitative work settings, felt that CSA was a violation of a child's right, and hence felt it was imperative for them to handle CSA cases that came into the agency's fold. In his own words,

CSA is a gross violation of children's rights and was incorporated in the mandate of <name of the agency> CSA is seen as violating children's right to protection and participation and affects their normal growth and development.

Besides direct intervention, four out of the nine agencies believed that their approach ought to focus on preventing CSA. For instance, an agency working on the issue of HIV/AIDS and ran safe-sex educational campaigns across public and private schools in the city, felt that CSA had to be incorporated into their campaign messaging, since it was an area that students were misinformed about. An agency, which runs a 24-hour national toll-free helpline for children in need of care and protection, found that a large number of calls they were receiving were CSA related necessitating an expansion of their organizational mandate. Two other agencies have been founded on the premise of raising awareness and breaking the silence on CSA through training programs and capacity building workshops in schools, shelter homes and other institutional settings for children.

Public hospitals on the other hand do not appear to exercise an element of choice with regards to assisting CSA victims. They often receive their case referrals from the Child Welfare Committee or the police. Given their expertise, they are responsible for conducting a thorough medical examination of the victims of sexual violence to provide evidence for legal court proceedings. Therefore in the words of the doctor at the maternity hospital,

CSA is a gruesome crime, a horrible act that is the breach of a basic right, which is conferred by the constitution. Most often kids are unaware of what is happening. No normal person can ever have such filthy thoughts, as the abuser is someone who is not in the right state of mind. The entire medical fraternity is aware and sensitive to the issues of sexual exploitation and sexual assault. As representatives of such a system created by society, they feel that CSA crosses the limit. The hospital staffs help the law; we provide evidence in order to bring the abuser to book.

Implicit in her statement is the notion that the medical fraternity contends with the brutality and magnitude of CSA cases coming into their fold, however their primary responsibility is to provide evidence for medico-legal court proceedings. Thus we can observe that most NGOs forayed into working in the field of CSA even though working in the field of CSA was not a part of their original organizational missions. Due to the sheer magnitude, prevalence and need of CSA case intervention and prevention, NGOs have expanded their original mission statements. Hospitals on the other hand owing to their medical expertise in uncovering evidence for court proceedings are mandated to handle CSA cases that are referred to them.

\section{CSA Case Description and their Help Seeking-Pattern}

Public hospitals receive their caseloads largely from the police and in a few instances through parents or the Child Welfare Committee. The police hospital exclusively handles cases that have been only referred by the police. This is a similar process for NGOs but unlike most hospital settings, NGOs also engage in outreach work for CSA case referrals. Additionally, since NGOs are more embedded within local communities, cases often get referred to them because of their earned reputation and legitimacy in the field of CSA. For instance the program manager of the NGO who runs a helpline for children in need of care and protection states, 
The outreach staff is involved in educating and spreading awareness about children's issues as well as allying with governmental bodies, public calling booth earners in terms of permitting children to make calls free of cost. There are an equal number of male and female outreach members to help both boys and girls.

The NGO CSA caseload ranged from two cases annually in one agency, to about four cases every six months in other agencies with an equal breakdown of cases across gender. According to the agency program managers, the ages of these children ranged from five to sixteen years. In contrast, hospitals handled larger CSA caseloads. For instance, the Multi-Disciplinary Child Protection Center manages forty to fifty cases annually, the maternity hospital manages on average three cases per month and the police hospital handles at least one case a day. The medical superintendents also cited that such cases occurred equally across gender with an age range of two years to sixteen years. A majority of the cases handled by both NGOs and public hospitals are of children hailing from impoverished, marginalized backgrounds. Regarding the nature of sexual abuse most agencies have largely handled cases of rape, fondling and sexual assault, as these cases require medico-legal intervention compared to non-touch forms of sexual abuse. According to the doctor in the Department of Gynaecology at the Maternity hospital,

A rape case in the medical context is understood as peno-vaginal intercourse. I have come across a case of a 5-year-old girl who had been sexually molested by her security guard and another case of a minor girl who had been subjected to sodomy. Both victims were described as small petite girls who were gullible and non-assertive.

It is important to understand the context under which children have disclosed their sexual abuse encounters. Several NGO program managers mentioned that children begin speaking about their sexual abuse encounters once they have developed a certain amount of trust and rapport with their caseworkers. In some cases, CSA is discovered accidentally through physical examinations conducted on children, while others have been well trained to recognize symptomatic patterns of CSA victims. Agencies, whose core focus is raising awareness about CSA, have also had disclosures of cases come forward to them post their trainings and workshops, and have subsequently referred such cases to direct service providers. For instance, the program coordinator of an organization that runs shelter homes for children living on the streets states,

When a child comes into the custody of the organization then they are not forced to undertake a medical test, as the organization would not like to intrude on their powerlessness. The best technique employed is talking to the child straight. There are other indicators of a child facing trauma/abuse such as some behavioural and medical conditions, which require immediate attention.
Safety of the child is a priority at most NGOs especially if they are providing residential facilities for the victim of CSA. Multiple agencies hire in-house counsellors who are in close communication with the children, and on occasion hire a visiting psychiatrist for psychiatric intervention in the most severe cases. Extra precautions are taken with regards to assigning caseworkers for such children, for instance, the coordinator of the agency that rescues minors from human trafficking states,

We as an organization take extra precautions and have multiple screenings while hiring male employees and in addition, for any counselling sessions with the child no member is allowed to close the door behind them.

The nature of the setting of such an abuse tends to cut across all contexts such as homes, schools, shelter homes, and public parks amongst others. The abusers are seen to be older people who are powerful and have established a prior, trusting relationship with the minor. The common symptoms faced by CSA victims include being withdrawn, aloof, inability to concentrate, insecure and hostile. The coordinator of an agency that works with runaway girls stated,

The child usually suffers from mood swings, tempers tantrums, is stressed due to overprotection from the family and engages in attention seeking behaviours. While dealing with the cases through the year, one has come to see that most often the families are the perpetrators, and if a girl in the family has faced such an abuse then the family places several restrictions on her in the name of overprotection. Family support for a girl is very much required during the legal proceedings.

The above statement is indicative of the patriarchal norms that are at play within Indian households, wherein the familial response to CSA intervention is to restrict and overprotect their child, especially if the victim is a girl. Gender differences attributable to the way Indian children are socialized has led to varied CSA disclosure patterns across gender as stated by program coordinator of the agency that shelters street children,

The victims are both boys and girls but there is a difference in the behavioural and symptomatic pattern of disclosure. Girls because of their socialization and the acceptance that they can be subject to sexual violence feel comfortable sharing their experience of sexual violence, whereas boys put on a façade and it becomes harder to identify such cases amongst boys.

At public hospital settings, in a majority of the cases the disclosure surrounding CSA has occurred in another setting. However in a few instances, medical superintendents pointed out that they suspected CSA physical symptoms such as bruises or scars during a regular physical examination of the child. Often, hospital staff has to contend with the impact that such an abuse has 
on a child such as persistent fear and paranoia, discomfort being around other adults besides their parents as they experience both physical pain and mental anguish. With regards to CSA disclosure across gender, the police surgeon at the Police Hospital states,

The parents usually go into deep trauma and often the child is unaware of what is happening. It is mostly more traumatic for a girl when she realizes that she has lost her virginity at such a young, tender age.

The above findings across both formal institutional care settings emphasize the need for timely and sensitive intervention especially in the light of gendered norms that these institutions operate within. In addition, we can observe a variation in the kinds of contexts of CSA disclosure, with a difference in the setting of the abuse and profile of abusers, thereby making CSA intervention a very challenging and complex process.

\section{CSA Intervention \& Prevention}

Most NGO's engaged in direct handling of CSA cases stated that they adhered to the legal proceedings and policy guidelines put forth in the Juvenile Justice Act. On coming in contact with a case of CSA, the child's first point of contact is to receive a thorough medical examination at a health centre or hospital. This is preceded by registering the case with the police and filing a First Information Report ${ }^{4}$ after which the child is presented before the Child Welfare Committee. The Child Welfare Committee usually decides the outcome of the case based on the evidence provided, and the child can be placed either in a Government shelter facility or a NGO can petition to shelter the child. As stated by several direct service providers, one of their frontline staff members is present throughout the child's court proceedings and they continue to provide psychosocial counselling for both the children and their guardians. This was resonated by the program manager of the organization that works with runaway girls,

The <name of the agency> worker accompanies the child through all the session's court proceedings as well as with the introductory meeting with the lawyer wherein the worker is with the child every step of the way. We have also been a complainant and a witness of cases.

Based on the decisions regarding whether the victims and their families want to press charges against the perpetrator, on having received consent from the victims and their guardians, the case goes into medico-legal proceedings usually handled by an external lawyer or public prosecutor. As stated in the above quotation, some organizations have been the complainants and witness of

4 First Information Report is a written document prepared by the police when they receive information about the commission of a cognizable offence, often lodged by the victim's party (Commonwealth Human Rights Initiative, n.d.) cases usually in circumstances when the child has no other form of social support or guardianship. NGOs are more adept at helping children meander through multiple stakeholders in the child welfare machinery. However NGOs have been critical of the level of coordination that exists between these stakeholders. For instance, the program coordinator of the agency catering to runaway girls in her statement below highlights the insensitive nature of handling CSA cases across the child welfare machinery,

There is a problem of communication and networking between the police, hospital and the public prosecutor. The Special Juvenile Police Unit officials do not find a gynaecological test and a medical check-up necessary, as they do not know the significance of a medical statement in terms of whether it is positive or negative. Even while a gynaecological check-up is done, it is a very unpleasant time for the victim as the environment is not child friendly for instance in one case, the doctor asked the girl to lift up her skirt.

Besides direct service provision for victims of CSA, NGOs believe that it is equally important for them to engage in sensitization trainings and awareness building amongst their staff on topics such as symptom identification and appropriate case management. Some agencies are teaching children self-protection measures such as "good touch and bad touch", as well as encouraging children to come forth and disclose their CSA in confidence with an adult they feel comfortable approaching. These organizations also believe in creating sensitivity and awareness amongst key stakeholders such as the police, Child Welfare Committee, Special Juvenile Police Unit etc. For instance, an agency specified the kind of training rendered to the Special Juvenile Police Unit which included components such as, i) what is CSA, ii) who is an abuser, iii) common myths dispelled, iv) signs and symptoms, and v) how to speak to a child and file an ideal First Information Report. It was observed that several agencies were getting involved in larger citywide and national coalitions on advocating for more stringent legal implications for CSA abusers. For instance, a NGO working with street children organized a city-level seminar called 'Violence Against Girls' which highlighted cases of sexual abuse and family violence and protested on the streets to grant justice for a mentally challenged girl who had been raped on a public train.

Organizations that are primarily focused on spreading awareness on the issue of CSA among the general population do so through mediums such as street play performances, puppetry shows, film screenings, seminars and citywide events such as the annual marathon. An organization that built a research-informed program titled 'Help Eradicate Abuse through Learning' focused on creating CSA prevention modules for parents, teachers and children. The modules content included the prevalence of CSA, how to provide age-appropriate 
information to children about CSA, how to keep a child safe, be alert to symptoms and what to do in the case of a child disclosing their abuse. Another agency focuses its efforts on improving the capacity building of counsellors handling CSA cases, and engages in healing and psychosocial counselling techniques, such as trauma-informed Eye Movement Desensitization Processing.

Out of the three public hospitals it was observed that the Multi-Disciplinary Child Protection Center adopted a more comprehensive approach to handling cases of CSA, as their emphasis encompassed providing psychosocial counselling along with medico-legal intervention for victims. The Multi-Disciplinary Child Protection Center services are fivefold, 1) Health care: Multi-Disciplinary Child Protection Center conducts a sensitive thorough treatment, evidence collection and ossification of cases considered high risk to garner all the probable and possible causes of abuse, 2) Psycho-social care and counselling: Provision of support to the child and guardians which is non-judgemental, confidential, supportive and builds a relationship, 3) Family engagement: Works closely with the families of victims to prevent re-victimization, minimize the child's vulnerability and strengthen child support, 4) Networking: Network with police, lawyers, Child Welfare Committees, NGOs etc. for an integrated team response for long term care, and 5) Research informed practice: Build best practices and lessons learned from multi-systemic experience. In order to achieve their services, the Multi-Disciplinary Child Protection Center staff adopts three key strategies, which involve a Quick Response
Team that comprises of members from relevant hospital departments for information sharing and decision-making. Secondly they have formed an advisory board comprising of experts from medical, legal, social work and psychology to support and scale up the work on child protection, and finally the Multi-Disciplinary Child Protection Center is involved in skill building and training initiatives of multiple personnel involved in this integrated multidisciplinary approach.

Other hospital settings are largely seen to provide assistance to victims from the perspective of providing evidence for legal case proceedings. For instance, according to the doctor of the Multi-Disciplinary Child Protection Center,

Cases of sexual assault or rape, which come into the police's custody, are referred to the Police Hospital. Often the purpose of taking them to such a hospital is just for collecting forensic samples and not providing mental and physical treatment to the child.

Steps in the process of how a medical examination is conducted and the procedure of evidence collection are provided in table 4.3.1, which compares and contrasts the procedures at the maternity and the police hospital alike.

From Table 4.3.1 we can observe that even though both hospital settings are primarily focused on garnering evidence "to book the abuser", the maternity hospital, adopts a more thoughtful approach to evidence gathering compared to the police hospital, whose primary focus is to garner evidence. This is explicated by what was stated by the doctor at the maternity hospital,

Table 4.3.1. Key steps followed by hospital staff for CSA medico-legal cases

\begin{tabular}{|c|c|}
\hline Maternity Hospital & Police Hospital \\
\hline $\begin{array}{l}\text { Information sought about the alleged history of sexual } \\
\text { molestation or act from the victim }\end{array}$ & $\begin{array}{l}\text { Victim consent sought if victim is above age 12; guardian consent sought if } \\
\text { victim is below age } 12\end{array}$ \\
\hline General account of patient's condition made & Separate proforma's carried out for both the victim and the accused \\
\hline $\begin{array}{l}\text { Physical injuries determined especially in the genital region; } \\
\text { medical care provided if injuries are life-threatening }\end{array}$ & $\begin{array}{l}\text { Accused proforma includes: } \\
\text { - Examination of injuries incurred to private parts } \\
\text { - Potency test conducted } \\
\text { - Oral history noted } \\
\end{array}$ \\
\hline Informs the police & $\begin{array}{l}\text { Victim Performa oral history probes details about the incident such as Where } \\
\text { did the incident take place? Was it consented to? When was the last } \\
\text { menarche? }\end{array}$ \\
\hline $\begin{array}{l}\text { Guardian and victim consent sought for medico-legal } \\
\text { intervention; examination conducted in the presence of } \\
\text { witnesses }\end{array}$ & \multirow{3}{*}{$\begin{array}{l}\text { Victims thorough medical examination include } \\
\text { - Victims clothes are collected as a sample } \\
\text { - Victim's built, height, weight, mental state and gait is noted } \\
\text { - Chemical analysis of vaginal smear } \\
\text { - Identification marks of injury on private parts } \\
\text { - Examination of abdomen and anus } \\
\text { - Physical, dental, ossification and secondary sexual characteristic tests } \\
\text { conducted for age verification }\end{array}$} \\
\hline $\begin{array}{l}\text { Thorough medical examination (duration of 2-3 hours) } \\
\text { includes: } \\
\text { - Samples collected from victim's clothes, oral saliva swabs } \\
\text { - Account of injury marks such as love bites, broken nails, } \\
\text { hair samples and genital area samples }\end{array}$ & \\
\hline $\begin{array}{l}\text { Samples are collected, sealed and submitted to the police in } \\
\text { front of the hospital administration }\end{array}$ & \\
\hline
\end{tabular}


The most important aspect looked into is to heal the child of his/her mental and physical trauma. More importantly such an issue is looked upon as social stigma. Even if the child loses the medico-legal aspect of the case, doctors and parents feel better if the child has recovered or healed.

At the Maternity hospital, the involved departments that handle CSA cases include gynaecology, paediatrics and psychiatry. The duration of stay of the victim at the maternity hospital depends on the type of injury incurred. For instance a small vaginal tear takes approximately a week to heal, and if a child's anal sphincter is torn then they are placed on a liquid diet for five days. However the emphasis of the maternity hospital is to continue with the medical and psychosocial treatments, even if the court case is discontinued.

Hence one can observe differences in the level of compassion, sensitivity and understanding of CSA across hospitals while handling medico-legal cases. Public hospitals compared to NGOs are understood as specialists in the field of CSA primarily focused on medically examining victims for evidence gathering, whilst NGOs focus on case management and the provision of psycho-social counselling for victims of CSA.

\section{Gaps \& Felt Needs}

Almost all NGOs emphasized issues of worker burnout and feeling overburdened and under supported within their agencies. Quality training specifically with respect to self-reflection, compassion towards CSA victims and working in the best interests of the child were seen to be lacking. Several agencies spoke of their geographical limitations in terms of reaching out to CSA cases located in far-flung regions of the city, beyond their jurisdictional capacity. For instance, the program manager at the agency that works for the cause of runaway girls' states,

There is a lack of manpower as such work requires tremendous paper work and documentation to handle such cases especially those which are medico-legal in nature. One requires expertise to handle such cases. We need a team of professionals to handle such cases as often the case is shuttling between systems.

NGOs that engage in direct case intervention highlighted several complications in the process of handling medico-legal cases. Shame and stigma are often seen to plague families during the course of a medico-legal investigation, and on occasion the guardians owing to overwhelming pressures faced by the abusers tend to drop the investigation all together. Legal proceedings are viewed as onerous and often take close to two to five years to receive summons, which leads to surmounting frustration and a lack of faith in the system on the side of the victims' party. Organizations often expressed discomfort with the way the child's case was handled callously by the police, medical centers, and public prosecutors as tactics such as intimidation and direct questioning often lead to the child feeling re-victimized. For example, victims of CSA as noted by the agencies, often carried a sense of guilt as they are often confronted with obtuse statements such as, "Why were you outside? What were you wearing? ”

Trauma informed care provision is important. Most agencies spoke of their limitations with respect to hiring an in-house lawyer. Rehabilitating a child into a shelter home was viewed as tedious, as often cases of CSA require more extensive services which personnel find burdensome. Engaging in consistent, long-term follow up with the child proved challenging for agencies given their limited funds, resources and manpower. For instance, the organization that rescues minors from child labour said,

If a child is rescued and rehabilitated to another shelter, there is no guarantee that that shelter is $100 \%$ safe. Also often shelters/NGO do not take up such cases, as they require tremendous care and support, which they do not have to offer.

NGOs engaged in the preventive aspects of CSA highlighted their difficulty and frustrations in convincing authorities at institutions like schools and shelter homes with respect to conducting training on CSA awareness for their staff. Another agency felt that their awareness efforts only catered to specific audiences given that they lacked a multi-lingual approach, thereby limiting their outreach efforts. According to the program manager of the NGO who runs a helpline for children in need of care and protection,

The difficulties and problems faced while planning for CSA prevention initiatives, it needs to be made as simplistic as possible for children to understand and also the pamphlets need to be multi-lingual

Besides enhancing their outreach efforts and sensitizing the involved stakeholder, NGOs also spoke about improving their research and evaluation efforts with respect to understanding if their CSA intervention and prevention services are yielding positive outcomes for children and their guardians.

With regards to limitations faced by public hospitals, all three-hospital settings echoed the problem of timely forensic intervention in terms of evidence collection and corroboration. There are delays in the system owing to the police bringing in a case late or a lack of consent on the part of the guardian and the victims to conduct a medical examination. According to the doctor at the maternity hospital, high quality, detailed training seems to be amiss as she says,

The medical fraternity is positively aware of the issue but are unaware of the procedure. From a worker's point of view, regular training programmes need to be carried out with all the health care staff in order to provide the 
child with the best kind of attention. Good follow up needs to be carried out on behalf of the police and the legal system as well as timely intervention of cases. Sometimes we feel frustration because we, the medical staff perform our end of the work and then we watch and see that our efforts have gone to waste.

The Multi-Disciplinary Child Protection Center department head spoke of over-burdened staff members as besides looking at the medical and psychosocial care of the child, the staff is usually present for the court summons as well. Consultation and cross referencing of cases between different hospitals was cited as an important felt need.

\section{Discussion \& Implications}

\section{CSA Service Provision: Differences between NGOs and Public Hospitals}

The study findings have pointed to the fact that there is a difference in the kind of strategies adopted by NGOs and public hospitals for addressing CSA. This section will emphasize the variation in the kinds of CSA prevention and intervention services carried out by NGOs and public hospitals, in terms of capacity and scales of operation and the universality and resourcefulness of services.

\section{Capacity and Scales of Operation}

Scales of operations look different at both sets of institutional care. Public hospitals tend to have larger caseloads compared to NGOs, attributable to the fact that hospitals have a lot more resources, manpower and reach of the general population (wherein CSA is discovered as a part of a regular physical examination). As showcased in the findings, a majority of the NGOs forayed into the field of CSA because of the magnitude and prevalence of the problem amongst the children and youth they served. Given that several agencies were not founded on intervening and preventing CSA, they often contended with competing priorities of handling CSA cases versus upholding their original missions. CSA cases need to be handled with a lot more care and sensitivity, which require a thorough, follow-up assessment of the case. NGOs simply do not have the resources or the specialized manpower to continue such intensive engagement and hence this proves to be a serious limitation in the third sector. Similarly hospital settings barring the Multi-Disciplinary Child Protection Center facility, do not engage in the follow-up of CSA cases since their primary task is to provide medical evidence for court proceedings. Hence despite handling larger caseloads than NGOs, provision of continued services for victims of CSA and the affected parties is an area that needs attention. These results resonate with previous studies which highlight that therapeutic services often have short-term, unstable and insecure funding arrangement that often interfere with CSA service provision. Organizations often search for new sources of funding and tend to spend large amounts of their time to renew and renegotiate existing funding, which in turn interferes with the actual day-to-day delivery of services to children and young people (Allnock et al., 2012).

NGO and public hospital providers often reported that the demand for services exceeded their capacity, which suggests that many children do not get the help and support they need to help them cope with and overcome the harmful long-term consequences of CSA. Specialist services are not only too few but also tend to be offered too late, as several staff mentioned timely intervention for collecting forensic evidence being a major limitation. Shortfalls in resources resulting from such unstable and short-term funding were of significant concern to managers across all sectors of provision, as they interfere with the nature of therapeutic work, which is more long-term. As highlighted in the literature, early responses save organizations money in the long run and hence timely CSA intervention to arrest future complications from arising is very important.

\section{Universality and Resourcefulness of Services Provided}

NGOs adopt a holistic approach to working in the field of CSA compared to public hospitals. NGOs engage in work that is both prevention and intervention oriented and operate from a child rights perspective that is, working in the best interest of the child. That is not to state that public hospitals do not strive to work in the best interest of the child, but their area of expertise in the field of CSA is to garner medical evidence for medico-legal court proceedings. Public hospitals are more concerned with timely medical intervention in order to provide better evidence to the court, while NGOs tend to focus on providing the relevant care and support, largely in the form of psycho-social counselling to victims and their affected parties. In addition it appears that NGOs due their hands on, outreach efforts tend to be the first point of contact for victims of CSA. Thus NGO professionals are and ought to be more adept at identifying CSA symptoms as well as developing a sense of trust and rapport with the victim so as learn more about their disclosure patterns as well as inform them about the legal recourse they can choose to take. NGOs as observed in the data tend to maintain a close relationship with the Child Welfare Committee as well as other key stakeholders such as the Special Juvenile Police Unit, attorneys, amongst others. NGOs often accompany the CSA victim right from their first medical examination at a medical setting, right through their court proceedings and in some instances pose as case witnesses. Public hospitals do not engage in such outreach or networking measures as NGOs do. There 
appears to be an interface between NGOs and public hospitals, as stated by some NGOs who mentioned that when cases under their care become medico-legal in nature they often take their clients to seek medical help and/or get medically examined for forensic evidence. Interestingly, none of the public hospitals spoke about their interface with NGOs with respect to CSA intervention.

NGOs more than public hospitals, are working creatively to intervene and prevent CSA. Evidence from the study highlights how NGOs are striving to use alternate mediums like street theatre, movie screenings, the famous "Mumbai Marathon" as ways and means to spread awareness and education on CSA. For example, the NGO that works in the field of adolescent sexual health and awareness emphasized that they are educating parents at schools through Parent-Teacher meetings as well as at corporate events at their workplaces (for parents who cannot attend meetings at schools) about how best to have conversations about CSA with their child and what are some of the common symptoms associated with CSA. NGOs are also focused on educating children directly by building age-appropriate modules for children and partnering with schools and child welfare institutions to raise awareness. More recently NGOs are utilizing social media outlets like YouTube, Facebook amongst others to create short videos about CSA identification for adults and children alike. In addition, as evidenced in the study, several media outlets are publishing articles on CSA, necessitating an urgency to intervene (Arpan, 2014; Human Rights Watch, 2013).

\section{Study Implications and Recommendations}

Despite the progress being made in the field of CSA, there are still gaps in providing assistance to affected children and families. Because there are multiple agencies involved, the gap is rendered even more complex. To unravel these complexities, and render assistance and services in a more effective manner, it becomes imperative to recognize and document issues that have emerged from the findings with regards to CSA intervention and prevention, specifically in terms of the provision of trauma informed services, improving training and capacity building, encouraging multi-sectoral collaboration as well as strengthening gaps in the implementation of the Protection of Children from Sexual Offences Act of 2012.

\section{Trauma Informed Service Provision}

Both NGOs and public hospitals emphasized the issue of victim blaming and intimidating tactics used while handling CSA cases across institutional settings. There is often a dilemma with respect to whether evidence collection is to be continued in order to help bring the perpetrator to justice or be stopped considering the child's unease and resistance. The findings corroborate with the literature that one of the most important reasons why children and their relatives choose not to come forward for help, is a fear that they will not be treated sympathetically largely due to intimidating interviews by police officers, degrading and painful medical examinations, and coercion by perpetrators to drop charges (Human Rights Watch, 2013). Bhaskaran \& Seshadri (2016), recommend that in order to make the process less threatening for children and their families, it is important to assign a primary caseworker who could accompany the child in all referrals, procedures and enquiries and be a familiar, consistent figure in the process. In addition they suggest the use of trauma-informed forensic interview protocols such as the Corner house Forensic Interview or National Institute of Child Health and Human Development protocols so that the statement obtained from the child is done in a developmentally sensitive, unbiased and truth-seeking manner that will support accurate and fair decision-making in the criminal justice and child welfare systems. Other studies have merited the use of evidence-based intervention treatments for CSA such as trauma-focused-Cognitive Behavioural Therapy proven to reduce a child's negative and emotional behavioral responses to sexual victimization (Cohen, Mannarino \& Deblinger, 2006). In addition, the use of multiple forensic interviews with suspected victims will provide victims with a fair opportunity to share their disclosure stories at their pace and adults with the recourse to protect them (Azzopardi, Madigan \& Kirkland-Burke, 2014).

\section{Training and Capacity Building}

The current study in corroboration with other studies (Kumar et al, 2012) has laid emphasis on the traditional conservative family and community structures surrounding CSA that seep into institutional care structures in India. While the Indian media and NGOs nationally are playing a leading role in raising awareness about CSA across the country, it is vital to address patriarchal norms that silence CSA victims and their families. Sensitization trainings and workshops on CSA case intervention were seen as an area of improvement. Service providers need to approach CSA as an experience and not a disorder (Bhaskaran \& Seshadri, 2016). Ideally, all health workers (i.e. nurses, physicians, social workers, mental health professionals) who come into contact with victims of sexual violence should receive appropriate training; this applies particularly to nurses and physicians who conduct physical examinations of victims of sexual violence (WHO, 2003). In addition, drawing from the study findings, beyond sensitizing the child welfare machinery about the content of CSA intervention and prevention, emphasis ought to be placed on raising awareness about their inherent caste, class, cultural and gender biases they have with respect to handling cases of CSA. This is especially pertinent in formal care settings like Police Hospitals, which as evidenced from the study has the highest caseload of CSA victims but showcased the most insensitive and biased response towards CSA victims. 
Given the pluralistic nature of Indian society, the research also points towards making capacity building and training initiatives multi-lingual in order to amplify the message surrounding CSA.

\section{Multi-sectoral Collaboration}

In order to tide over shortfalls in provision of services due to staff feeling overburdened especially with regards to a follow-up of cases, studies have stressed the impetus for an integrated collaborative setup. Experts recommend the creation of multidisciplinary centers in at least one government hospital in every district staffed with trained personnel and equipped to provide integrated, comprehensive, gender-sensitive and child-friendly treatment, forensic examinations, counseling, and rehabilitation for children that suffer sexual abuse (Human Rights Watch, 2013). The Multi-Disciplinary Child Protection Center described earlier in the findings can be touted as one such model. Bhaskaran \& Seshadri (2016) propose that it is imperative to work as a part of a multidisciplinary team by ensuring a strong liaison of medical, psychiatric, child protection and legal systems to effectively assess and manage CSA cases. Services aspire to work collaboratively with other organizations, and activities such as signposting, referring to and consulting with other professionals are occurring regularly (Allnock et al, 2012). Assessment, establishment and management of CSA cases are filled with uncertainty. Therefore, in dealing with conflicting needs and goals, the clinician needs to maintain a continuous and unwavering focus on the child. Such a child-centric approach entails at a primary level, understanding the child's experience, her needs and desires and planning interventions from a right-based perspective. At a deeper level, it entails examining all related decisions and interventions with regard to family, legal and other systems from the perspective of the child's best interests, namely her safety and protection, and her immediate and future developmental trajectories and goals (Bhaskaran \& Seshadri, 2016). Additionally research has shown that high quality facilities for providing medical services to sexual assault victims are characterized by a number of key features, namely, they are accessible, secure, clean and private (WHO, 2003).

\section{Strengthening Legal Lacunae}

The implementation of the Protection of Children from Sexual Offences Act of 2012 was a promising step by the Government with respect to CSA intervention and prevention. As the study was conducted prior to the implementation of the Act, future research can try and gauge how the Act has impacted service provision and delivery across such settings especially as the Act recommends the adoption of a multi-sectorial approach. However as Bhaskaran and Seshadri (2016) have rightly pointed out that even though this Act is an important and comprehensive piece of legislation, it ought to be reviewed and revised based on the experience of its enactment. Merely enacting legislation will not be enough unless this is followed by strict enforcement of the law with accountability. Even though this study was conducted prior to the implementation of the Act, the findings from this study could provide insights into how the Act's machinery can be strengthened. The Protection of Children from Sexual Offences Act ought to generate a national guideline for management of CSA cases, which incorporates a multidisciplinary approach and ensures an effective liaison of medical, psychiatric, child protection and legal systems. This can effectively reduce the re-traumatisation while ensuring safety and justice for the children and their families (Bhaskaran \& Seshadri, 2016).

\section{Future Research in the Field of CSA}

In this era of increased demand for accountability and evidence-based practice, understanding current treatment practices, the extent to which they align with evidence-based practice, and the factors that influence the use of evidence-based practice are crucial for knowledge translation purposes in the field of CSA (Czincz \& Romano, 2013. As suggested by Allnock et al., (2012), gathering more evidence about sexual abuse assessment and provision would form a useful extension to the data currently collected through any national mapping process undertaken. The research highlights the need for more information on the range and effectiveness of different types of therapeutic support for children and young people who have experienced sexual abuse. The research points to the need to improve and expand our knowledge of a wider range of therapeutic support models, particularly taking into account young people's own views about the services they receive and the support they would like to have. Another unexplored area as cited in the literature (Schonbucher et al., 2014) would be tapping into understanding the kinds and sources of informal social support provided to victims of CSA in their own communities, given the limitations of case follow-up by formal institutional settings like NGOs and public hospitals. Future research could also focus on examining how service provision varies across different contexts such as urban and rural settings, public and private settings and how do demographic characteristics like caste, class and gender affect CSA service provision.

\section{Conclusions}

The study emphasizes the critical role played by NGOs and public hospitals with respect to CSA case intervention and prevention. NGOs offer more holistic services in terms of case management and psycho-social support for CSA victims and their families, while public hospitals largely focus on garnering medical evidence for court proceedings. 
Multi-sectoral collaboration as prescribed in the 2012 Protection of Children from Sexual Offences Act would improve timely and quality service provision to victims of CSA. Awareness generation on CSA and sensitizing the child welfare machinery on how best to intervene and prevent CSA will help break the silence surrounding CSA in a traditional, conservative society like India and shift the conversation from, Log Kya Kahenge (translated to What will people say? ) to Log Yahin Kahenge (translated to This is what people will say?).

\section{Acknowledgements}

I am grateful for the assistance provided to me by the Forum Against Child Sexual Exploitation (FACSE), an advocacy group operating in Mumbai, India.

\section{REFERENCES}

Alaggia, R \& Krishenbaum, S (2005). Speaking the Unspeakable: Exploring the Impact of Family Dynamics on Child Sexual Abuse Disclosures. Families in Society: The Journal of Contemporary Social Services: 86 (2)

Allnock, D., Radford, L., Bunting, L., Price, A., Morgan-Klein, N., Ellis, J., \& Stafford, A. (2012). In Demand: Therapeutic Services for Children and Young People Who Have Experienced Sexual Abuse, Child Abuse Review, 21, 318-334.

Arpan (2014). Between the Line- An Analysis of Media Reportage on Child Sexual Abuse. Mumbai: Arpan.

Azzopardi, C., Madigan, S., \& Kirkland-Burke, M. (2014). Sexual Abuse Forensic Evaluation with Young Children: Program Outcomes and Predictors of Disclosure. Journal of Child Custody, 11, 304-324.

Babbie, E. (2010). The practice of social research (12th ed.). Belmont, CA: Wadsworth.

Back, S., Jackson, J., Fitzgerald, M., Shaffer, A., Salstorm, S., \& Osman, M. (2003). Child sexual and physical abuse among college students in Singapore and the United States. Child Abuse and Neglect, 27(11), 1259-1275.

Baginsky M. (2001). Counselling and Support Services for Young People Aged 12-16 who have Experienced Sexual Abuse - A study of the provision in Italy, the Netherlands and the United Kingdom. London: NSPCC.

Belur, J. \& Singh, B.B. (2015). Child sexual abuse and the law in India: a commentary. Crime Science, 26(4), 1-6.

Berelson, B. (1971). Content analysis in communication research. New York: Hafner.

Bhaskaran, T.S., \& Seshadri, S.P. (2016). Child Sexual Abuse-Clinical Challenges and Practical Recommendations. Journal of Indian Association on Child \& Adolescent Mental Health, 12(2), 143-161.

Bhullar, D.S. (2014). Child Sexual Abuse \& Medical Professionals. Journal of Punjab Academy of Forensic Medicine \& Toxicology, 14(2), 73-75.
Carson, D., Foster, J., \& Tripathi, N. (2013). Child sexual abuse in India: Current Issues and Research. Psychological Studies, 58(3), 318-325.

Choudhury, R. (2006). Understanding family life in India. In A. Chowdhury, D. K. Carson, \& C. K. Carson (Eds.), Family life Education in India: Perspectives, Challenges, and Applications (pp. 31-57). Jaipur: Rawat Publications.

Cohen, J., Mannarino, A., \& Deblinger, E. (2006). Treating trauma and traumatic grief in children and adolescents. New York: Guilford Press.

Common Wealth Human Rights Initiative (n.d.). First Information Report (FIR) and You. New Delhi: Common Wealth Human Rights Initiative. Retrieved on 8/3/2016 from http://www.humanrightsinitiative.org/publications/police/fir.pdf.

Crisma, M., Bascelli, E., Paci, D., \& Romito, P. (2004). Adolescents who experienced sexual abuse: Fears, needs and impediments to disclosure. Child Abuse and Neglect, 28, 10351048.

Czincz, J. \& Romano, E. (2013). Childhood Sexual abuse: community-based treatment practices and predictors of use of evidence-based practices. Child and Adolescent Mental Health, 18(4), 240-246

Graneheim, U. H., \& Lundman, B. (2004). Qualitative content analysis in nursing research: Concepts, procedures and measures to achieve trustworthiness. Nurse Education Today, 24 (2), 105112.

Hiranandani, N. (August, 2017). The deafening silence of child abuse. Indian Express. Retrieved from http://indianexpress.com/article/blogs/the-deafening-silence-of-c hild-abuse-2980397/

Human Rights Watch (2013). Breaking the Silence Child Sexual Abuse in India. USA: Human Rights Watch.

Jaswal, S. (2005). Child and Adolescent Sexual Abuse in Health Facilities. Indian Journal of Social Work, 66(4)

Jha, P. (September, 2017). What will it take to end child sexual abuse in India? Open democracy. Retrieved from https://www.opendemocracy.net/5050/prita-jha/ending-child-sex ual-abuse-india

Juvenile Justice (Care and Protection of Children) Act, (2015). New Delhi: Ministry of Law and Justice, Government of India, No.56 of 2000, Retrieved from

http://www.indiacode.nic.in/acts-in-pdf/2016/201602.pdf on $7 / 28 / 2016$

Kacker, L., Mohsin, N., \& Dixit, A. (2007). Study on Child Abuse: India 2007. New Delhi: Ministry of Women and Child Development, Government of India.

Krippendorff, K. (2012). Content analysis: An introduction to its methodology ( $3^{\text {rd }}$ Ed.). Thousand Oaks, CA: Sage.

Kumar, A., Pathak, A., Kumar, S., Rastogi, P., \& Rastogi, P. (2012). The Problem of Child Sexual Abuse in India Laws, Legal Lacuna and the Bill-PCSOB-2011. Journal of Indian Academic Forensic Medicine, 34(2), 170-175.

Marshall, C. \& Rossman, G.B. (1999). Designing qualitative research $\left(3^{\text {rd }}\right.$ ed.). Thousand Oaks, CA: Sage.

Morrison, N. C., \& Clavenna-Valleroy, J. (1998). Perceptions of 
maternal support are related to self-concept and self-report of depression in sexually abused female adolescents. Journal of Child Sexual Abuse, 7, 23-40.

Panchal, T. \& Shah, N. (1997). Documentation of Police Cases of Sexually Abused Girls Under 10 years, Tata Institute of Social Sciences Mumbai

Prabhu, S. (2008). Dealing with Child Sexual Abuse: Child Line's Intervention. Project Report for MA in Social Work, TISS, Mumbai

Recovery and Healing from Incest (RAHI) (1998). Voices from the Silent Zone- A Study on Women's Experiences of Incest and Childhood Sexual Abuse. New Delhi: RAHI.

Roland A, (1988). In search of self in India and Japan: Towards a cross-cultural psychology. Princeton, NJ: Princeton University Press.

Saraswathi TS and Oke M, (2013). Ecology of adolescence in India: Implications for policy \& practice. Psychological Studies, Vol. 58, No. 4, pp. 353-364.

Save the Children \& Tulir Center for Prevention and Healing of Child Sexual Abuse (CPHCSA) (2006). Doesn't Every Child Count? Research on Prevalence and Dynamics of Child Sexual Abuse among School Going Children. Chennai: TULIR CPHCSA.
Schnonbucher, V., Maier, T., Mohler-Kuo, M., Schnyder, U., \& Landolt, M.A. (2014). Adolescent Perspectives on Social Support Received in the Aftermath of Sexual Abuse: A Qualitative Study. Archives of Sexual Behavior, 43, 571-586.

Stoltenborgh, M., van Ijzendoom, M., Euser, E., \& Bakermans-Kranenburg, M. (2011). A global perspective on child sexual abuse: meta-analysis of prevalence around the world. Child Maltreatment, 16(2), 79-101.

United Nations Children's Fund (UNICEF). (2012). The state of the world's Children 2012 - Children in an Urban World. New York: UNICEF.

Verma S and Saraswathi TS, (2002).Adolescence in India: Street urchins or Silicon Valley millionaires? In: Brown BB, Larson R Wand Saraswathi TS, eds. The World's Youth: Adolescence in Eight Regions of the Globe. pp. 105-140, Cambridge University Press, New York, NY.

Viramani, P. (April, 2017). India shamed by silence on child sexual abuse within family. South China Morning Post. Retrieved from

http://www.scmp.com/comment/insight-opinion/article/2090397 /india-shamed-silence-child-sexual-abuse-within-family

World Health Organization (WHO) (2003). Guidelines for medico-legal care of victims of sexual violence. Geneva: WHO. 